\title{
Salicylate ototoxicity in patients with rheumatoid arthritis: a controlled study
}

\author{
JAMES T HALLA AND JOE G HARDIN
}

From the University of South Alabama Department of Medicine, University of South Alabama College 话 Medicine

SUMmARY Tinnitus or subjective hearing loss, or both, were reported by 61 of 134 (45\%) patients with rheumatoid arthritis (RA) taking regular salicylates and by 73 of $182(40 \%)$ untreated healthy subjects. In the patients with RA mean salicylate levels were not higher those with tinnitus than in those without tinnitus, but levels were significantly higher in those with subjective hearing loss than in those with no symptoms. Twenty five per cent of the patients wift RA had tinnitus or subjective hearing loss with salicylate levels $<1.42 \mathrm{mmol} / \mathrm{l}$. Audiometrie responses in 31 patients correlated poorly with symptoms. Tinnitus and subjective hearing loss may be too non-specific to be reliable as tools for adjusting the salicylate level into the therapeutic range.

Key words: acoustic nerve diseases, aspirin.

The major symptoms of salicylate ototoxicity are subjective hearing loss and tinnitus. ${ }^{12}$ In individuals with these symptoms audiograms typically show a raised threshold for all sound frequencies, usually in the range of $20-40 \mathrm{~dB}$, and the hearing loss is sensorineural. ${ }^{12}$ Symptoms and audiometric abnormalities are reversible within 72 hours of discontinuing salicylates. ${ }^{3}$ The degree of hearing deficit is roughly proportional to the serum salicylate level, and tinnitus has been noted to occur only with serum salicylate levels of $1.42 \mathrm{mmol} / \mathrm{l}$ or greater. ${ }^{124}$ The dose of salicylate required to produce a therapeutic or toxic level varies widely from individual to individual, ${ }^{1} 2{ }_{2} 56$ indicating that some type of monitoring tool is necessary to achieve a therapeutic level while avoiding toxicity. The salicylate ototoxicity symptoms of subjective hearing loss, and especially tinnitus, are widely used for this purpose'push to tinnitus, and, then back off slightly' having become a time honoured approach to salicylate therapy. ${ }^{1-47}$ The major problem with this tool is its lack of sensitivity; tinnitus may fail to occur in the presence of salicylate levels in the toxic range, especially in older individuals with a pre-existing high tone hearing loss. ${ }^{1-4}$

Accepted for publication 21 July 1987.

Correspondence to Professor Joe G Hardin, 2451 Fillingim Street, Mobile, AL 36617, USA.
We have also observed problems owing to the non-specificity of this tool. Patients with rheumatis disease who were not taking salicylates frequent reported subjective hearing loss or tinnitus, an $\oplus_{2}$ more confounding, patients who were taking salic $\overrightarrow{\vec{b}}$ lates often reported subjective hearing loss or tip nitus with subtherapeutic salicylate levels. Becaus these observations further challenge the validity of symptomatic salicylate ototoxicity as a tool for accurately adjusting the salicylate dose, the presegt study was undertaken in an effort to determine the specificity of subjective hearing loss and tinnitus as measures of the therapeutic or toxic serum salicylate levels.

\section{Subjects and methods}

S U B J E C TS

The test subjects were 134 consecutive patients witho definite or classical rheumatoid arthritis (RAN (American Rheumatism Association criteria) who reported the regular use of aspirin or a salicylate preparation for longer than a week with no change in the dosage schedule over the week before the study. Their mean age was $58 \cdot 3$ years (range $20-88)_{0}$ The control subjects were 182 healthy voluntee $\overline{6}$ who reported no regular salicylate (or aspirin) us $\Phi_{0}$ Their mean age was $34 \cdot 3$ years (range $20-61$ ). 
I N T E R V I E W

In a structured interview all subjects were questioned about recent symptoms of subjective hearing loss and tinnitus and previous history of ear disease or known hearing loss. Tinnitus was defined as a recurrent unilateral or bilateral ringing, roaring, or buzzing sensation with each recurrence persisting for five minutes or longer. Based on their response to these questions subjects were divided into four groups: (1) those with both subjective hearing loss and tinnitus; (2) those with tinnitus alone; (3) those with subjective hearing loss alone; and (4) those with neither.

\section{SALICYLATE LEVELS}

At the time of the interview blood was obtained from all of the 134 patients with RA for a serum salicylate determination. All salicylate levels were measured in one laboratory by the ultraviolet spectrophotometric method of Keller. ${ }^{8}$

\section{A U D I O M E T R Y}

Representative patients with RA from each of the four groups defined above were selected for audiometry. The audiological examination, including pure tone air and bone threshold testing, speech reception threshold testing, and speech discrimination testing, was performed by a certified audiologist under controlled conditions.

\section{STATISTICAL METHODS}

Statistical significance was calculated using $t$ tests on paired samples and $\chi^{2}$ tests on percentages for the four group comparison.

\section{Results}

The number of RA and control subjects in each of the four groups is shown in Table 1 . There were no

Table 1 Comparison of the prevalence of symptoms in rheumatoid arthritis and control groups

\begin{tabular}{|c|c|c|c|c|c|}
\hline \multirow{4}{*}{$\begin{array}{l}\text { Tinnitus (T) } \\
\text { Subjective } \\
\text { hearing loss } \\
\text { (SHL) }\end{array}$} & \multirow{2}{*}{\multicolumn{2}{|c|}{$\frac{R A(n=134)}{\text { No }(\%)}$}} & \multirow{2}{*}{$\begin{array}{l}\text { Mean age } \\
\text { of patients } \\
\text { with } R A\end{array}$} & \multirow{2}{*}{\multicolumn{2}{|c|}{$\frac{\text { Control }(n=182)}{\text { No }(\%)}$}} \\
\hline & & & & & \\
\hline & 46 & $(34)^{*}$ & & 46 & $(25)^{*}$ \\
\hline & 42 & (31) & & 51 & (28) \\
\hline \multirow{5}{*}{$\begin{array}{l}\text { Subgroups } \\
\text { (1) T and SHL } \\
\text { (2) T alone } \\
\text { (3) SHL alone } \\
\text { (4) Neither }\end{array}$} & & & & & \\
\hline & 27 & $(20)^{*}$ & 66 & 24 & $(13)^{*}$ \\
\hline & 19 & (14) & 56 & 22 & (12) \\
\hline & 15 & (11) & 68 & 27 & (15) \\
\hline & 73 & (55) & 55 & 109 & $(60)$ \\
\hline
\end{tabular}

${ }^{*}$ NS significant differences between the RA and control subjects with regard to any combination of these symptoms. Patients with RA in group 1 were significantly older than those in group $2(p=0.02)$ and group $4(\mathrm{p}<0 \cdot 01)$. Those with tinnitus (groups 1 and 2) were not significantly older than those without (groups 3 and 4); RA patients with subjective hearing loss (groups 1 and 3), however, were significantly older than those without (groups 2 and 4) $(\mathrm{p}<0.01)$.

Serum salicylate levels in the 134 patients with RA are given in Table 2. The mean level tended to be lower in the asymptomatic group than in the three groups with symptoms, but there was a significant difference only between groups 3 and 4 . Subjects with tinnitus (groups 1 and 2) (mean salicylate level $1.27 \mathrm{mmol} / \mathrm{l})$ did not differ from those without (groups 3 and 4) (mean salicylate level $1.23 \mathrm{mmol} / \mathrm{l})$; the mean salicylate level in patients with subjective hearing loss (groups 1 and 3$)(1.47$ $\mathrm{mmol} / \mathrm{l})$, however, was significantly higher $(\mathrm{p}=0.02)$ than in those without (groups 2 and 4$)(1.17 \mathrm{mmol} / \mathrm{l})$. Most patients with tinnitus and subjective hearing loss or tinnitus alone had serum salicylate levels less than $1.42 \mathrm{mmol} / \mathrm{l}$. Only in the group with subjective hearing loss alone did the majority have levels greater than $1.42 \mathrm{mmol} / \mathrm{l}$. A total of 33 patients or $25 \%$ of the patients with RA had symptoms suggestive of ototoxicity with salicylate levels less than $1.42 \mathrm{mmol} / \mathrm{l}$.

Of the 134 patients with RA, 32 had an earlier history of ear disease or known hearing loss before salicylate use. These patients were older than those without prior ear disease (mean age $66 v 56$ years) and more often had tinnitus $(62 \% \vee 25 \%)$. Those patients with tinnitus and prior ear disease had a significantly lower salicylate level than those subjects with tinnitus and no earlier ear disease $(1.17 \mathrm{mmol} / \mathrm{l} v 1.38 \mathrm{mmol} / \mathrm{l}, \mathrm{p}<0.05)$.

Table 3 details the audiometric responses of 31 patients with RA and relates these responses to serum salicylate levels. A sensorineural hearing loss

Table 2 Mean serum salicylate levels and the number of patients having a salicylate level greater than $1.42 \mathrm{mmol} / \mathrm{l}$ in the 134 patients with rheumatoid arthritis

\begin{tabular}{llllll}
\hline Group & $\begin{array}{l}\text { Mean salicylate } \\
\text { level (mmol/l) }\end{array}$ & \multicolumn{2}{l}{$\begin{array}{l}\text { Number (\%) with } \\
\text { salicylate level: }\end{array}$} \\
\cline { 3 - 6 } & & $>1.42 \mathrm{mmol} / \mathrm{l}$ & $<1.42 \mathrm{mmol} / \mathrm{l}$ \\
\cline { 3 - 6 } & & 9 & $(33)$ & 18 & $(67)$ \\
(1) T and SHL & $1 \cdot 34$ & 8 & $(42)$ & 11 & $(58)$ \\
(2) T alone & $1 \cdot 21$ & 11 & $(73)$ & 4 & $(27)$ \\
(3) SHL alone & $1 \cdot 70^{*}$ & 30 & $(41)$ & 43 & $(59)$ \\
(4) Neither & $1 \cdot 14^{*}$ & & &
\end{tabular}

$T=$ tinnitus; SHL = subjective hearing loss.

${ }^{*} \mathrm{p}<0.01$. 
Table 3 Audiometric responses in relation to serum salicylate levels above and below $1.42 \mathrm{mmol} / \mathrm{l}$ in patients with RA taking salicylates

\begin{tabular}{|c|c|c|c|c|}
\hline & $\begin{array}{l}(1) \\
T \text { and } \\
S H L\end{array}$ & $\begin{array}{l}\text { (2) } \\
T \text { alone }\end{array}$ & $\begin{array}{l}\text { (3) } \\
\text { SHL alone }\end{array}$ & $\begin{array}{l}\text { (4) } \\
\text { Neither }\end{array}$ \\
\hline Number of patients & 10 & 8 & 5 & 8 \\
\hline \multicolumn{5}{|c|}{ Audiometric response } \\
\hline Normal & 0 & 4 & 0 & 3 \\
\hline \multicolumn{5}{|l|}{ Salicylate level } \\
\hline$>1.42 \mathrm{mmol} / \mathrm{l}$ & 0 & 1 & 0 & 2 \\
\hline$<1.42 \mathrm{mmol} / \mathrm{l}$ & 0 & 3 & 0 & 1 \\
\hline \multicolumn{5}{|c|}{ Sensorineural hearing loss* } \\
\hline mild & 4 & 1 & 4 & 4 \\
\hline moderate & 0 & 0 & 0 & 0 \\
\hline severe & 6 & 3 & 1 & 1 \\
\hline \multicolumn{5}{|l|}{ Salicylate level } \\
\hline$>1.42 \mathrm{mmol} / \mathrm{l}$ & 6 & 2 & 5 & 4 \\
\hline$<1.42 \mathrm{mmol} / \mathrm{l}$ & 4 & 2 & 0 & 1 \\
\hline
\end{tabular}

$\mathrm{T}=$ tinnitus; $\mathrm{SHL}=$ subjective hearing loss.

*Mild=pure tone thresholds indicating $25-40 \mathrm{~dB}$ hearing loss; moderate $=$ pure tone thresholds indicating $40-60 \mathrm{~dB}$ hearing loss; severe $=$ pure tone thresholds indicating $60-80 \mathrm{~dB}$ hearing loss.

was recorded in 24 of the 31 patients. About half of the patients with no symptoms or tinnitus alone had normal responses, whereas none with tinnitus and subjective hearing loss or subjective hearing loss alone did. Seventeen of the 24 subjects $(71 \%)$ with an abnormal audiogram had salicylate levels above $1.42 \mathrm{mmol} / \mathrm{l}$, although only 11 of the entire group of 31 patients had levels less than $1.42 \mathrm{mmol} / \mathrm{l}$.

\section{Discussion}

It had been estimated that 36 million Americans have tinnitus, ${ }^{9}$ and subjective hearing loss may be even more common. Our survey of a relatively young and healthy population indicated that $40 \%$ had one or both of these complaints. The slightly higher prevalence of tinnitus and subjective hearing loss in our RA population could have been due to their older age, which renders the difference between these two groups even less significant. Severity of symptoms was not addressed in this study, however, and it is possible that the patients with RA had more persisting tinnitus and more severe subjective hearing loss. In one study subnormal hearing was confirmed in one third of a small group of patients with RA not taking salicylates, suggesting that RA itself may cause hearing loss. ${ }^{10}$ These observations do suggest that simply inquiring about tinnitus and subjective hearing loss during the course of salicylate therapy in patients with RA may mislead the physician into adjusting the dosage into the subtherapeutic range.

Our patients were taking a variety of salicylate preparations in different dosages ranging from leş than $1 \mathrm{~g}$ to more than $4 \mathrm{~g} /$ day, but all claimed to bge taking them on a regular basis, and all had beein taking the drug for longer than a week. In this stude salicylate level measurements were not timed to reflect trough and peak levels consistently, but, 和 our information from the patient is correct, a steade state should have been reached, minimising diffe $\mathbb{B}$ ences between the two levels. ${ }^{6}$ Most symptomatis patients had a history of fluctuating tinnitus (as dig most symptomatic controls), and this study made n effort to temporally correlate waxing symptoms with immediate blood levels of salicylate as did that Mongan and colleagues. ${ }^{4}$ This study was not intende? to record that one can predictably induce tinnitus क्ष subjective hearing loss with certain dosages or blood levels of salicylate. We did show, however, that history of these symptoms over the preceding fe days correlates poorly with a single random serum salicylate measurement. In fact, most patients with these symptoms had levels less than the $1.42 \mathrm{mmol}$ cut off point suggested by Mongan and colleagues $\frac{\mathbb{R}}{2}$ This was probably due to the prevalence of tinnit度 and subjective hearing loss in the general population and the fact that few of our patients had levels above $2 \cdot 17 \mathrm{mmol} / \mathrm{l}$. The results of this study, howegego suggest that some individuals may develop salicy ate ototoxicity with subtherapeutic serum salicy?te levels, a possibility that requires further study.

Unfortunately, only 11 of the 31 subjects selecteg for audiometric studies had salicylate levels less tha $1.42 \mathrm{mmol} / \mathrm{l}$ (compared with 76 of the entire group of 134), and this fact may bias those observations Four of 11 subjects with a salicylate level less tha $1.42 \mathrm{mmol} / \mathrm{l}$ had a normal audiometric respons whereas 17 of 20 patients with a level greater than $1.42 \mathrm{mmol} / \mathrm{l}$ had an abnormal response. On the other hand, only three of the eight patients with no tinnitus or subjective hearing loss had a norma audiometric response, indicating a generally po $\vec{x}$ correlation between symptoms and audiometry. $\frac{3}{3}$

The results of this study tend to confirm the previous suggestion of Champion and colleagues that symptoms of ototoxicity are insufficiently spe fic to be a reliable indicator of a therapeutic serum salicylate level. ${ }^{11}$ Tinnitus and subjective hearin loss are little more common in patients with $\mathrm{R}$ A taking salicylates than in a normal untreated popul: tion. Symptoms suggestive of ototoxicity usual occur in patients with random subtherapeutic salictlate levels, and these levels, even when above 1. $\mathrm{mmol} / \mathrm{l}$, correlate imperfectly with symptoms audiometric responses. Older age and pre-existing ear disease render symptoms of ototoxicity ef pecially unreliable when attempting to use them adjust a salicylate level into the therapeutic rang 


\section{References}

1 Plotz P H. Aspirin and salicylate. In: Kelley W N, Harris E D Jr, Ruddy S, Sledge C B, eds. Textbook of rheumatology. 2nd ed. Philadelphia: Saunders, 1985: 725-52.

2 Paulus H E, Furst D E. Aspirin and other nonsteroidal antiinflammatory drugs. In: McCarty D J, ed. Arthritis and allied conditions. 10th ed. Philadelphia: Lea and Febiger, 1985: 453-86.

3 Myers E N, Bernstein J M, Fostiropolous G. Salicylate ototoxicity. $N$ Engl $J$ Med 1965; 273: 587-90.

4 Mongan E, Kelly P, Nies K, Porter W W, Paulus H E. Tinnitus as an indication of therapeutic serum salicylate levels. JAMA 1973; 226: 142-5.

5 Paulus H E, Siegal M, Mongan E, Okun R, Calabro J J. Variations of serum concentrations and half-life of salicylate in patients with rheumatoid arthritis. Arthritis Rheum 1971; 14: 527-32.

6 Levy G, Tsuchiya T. Salicylate accumulation kinetics in man. $N$ Engl J Med 1972; 287: 431-2.

7 Tugwell P, Hart L, Kraag G, et al. Controlled trial of clinical utility of serum salicylate monitoring in rheumatoid arthritis. J Rheumatol 1984; 11: 457-61.

$8 \mathrm{Keller}$ W J. A rapid method for the determination of salicylates in serum or plasma. Am J Clin Pathol 1947; 17: 415-7.

9 Yanick P. What is the hearing and tinnitus help assn.? Hear Instruments 1985; 36: 53 .

10 Heyworth T. Liyanage S P. A pilot survey of hearing loss in patients with rheumatoid arthritis. Scand J Rheumatol 1972; 1: 81-3.

11 Champion G D, Day R O, Graham G G, Paull P D. Salicylates in rheumatoid arthritis. Clin Rheum Dis 1975; 1: 245-65. 